\title{
Sport is king1: An investigation into local media coverage of women's sport in the UK East Midlands
}

\begin{abstract}
:
There has been a recent interest in research into national media coverage of female sport, particularly single events, but on-going sporting activities by women are rarely reported. This paper attempts to examine this subject at the local level, looking in general at women's sport and in particular at women's football in the East Midlands region of the UK. Quantitative methods were used to survey local newspapers and radio stations and interviews were carried out with a range of people relevant to the field of study. The topic of sports media is framed here with reference to research into masculinities and a socialist feminist approach is used to address problems. The data showed there was a significant and on-going imbalance in the amount of coverage and even some signs of a decline in women's football reporting, in spite of a national resurgence of the sport itself. The authors try to account for this and suggest further areas of future study.
\end{abstract}

Key words : women, sport, football, media, coverage, gender.

\section{Introduction}

The London 2012 Olympics were hailed by commentators as the 'women's games' (Brown 2012) when gender parity in events and media coverage seemed nearer than ever before. Before the roar of the crowds began to fade in the memory, pundits asked whether or how the bonanza of reporting for so-called minority sports could be sustained.

Media coverage of sport in the UK has proliferated in the last 10 years, with an explosion of dedicated radio and TV stations. Yet nationally, recent research showed that women's sport only accounted for $2 \%$ of newspaper sports reporting (WSFF 2009), far less women's football, and an estimated 5\% across all media (WSFF cited in Topping 2012). This study examines coverage in local media to see whether the picture differed there or was changing. It also observed the growing participation, interest and success around women's sport itself. The focusis on women's football because it is the biggest female team sport, (FA 2013) and reported to be the fastest growing sport in the UK (BBC 2007). However, in interview 2, sports journalist Sue Mott said she was pessimistic about change, warning that, 'Women's football is up against one of the great, cultural icons of our time: men's football, which dwarfs every other sport, large and small.'

The aim of the research was also to see how the struggle over gender relations played out in this arena; in particular in football, the national (men's) game, like ice hockey in Canada: 'one of the main sites for the contemporary challenge to the gendered landscape of sport,' (Theberge 2002, 292). This article notes gender problems and influences in business, institutions, culture and sport itself. It explores whether a post-modernist or structuralist approach is most relevant when dealing with the marginalisation of women in local sports news.

There have been various studies of national coverage of women's sport, but very little focus on the local level. Yet every story has to take place somewhere : every global sensation has to have a location, with its own, small scale media outlets. It is in 
local newsrooms where the stories and personalities are made. This investigation is an attempt to start digging into this rather secluded territory, largely ignored by analysts. The East Midlands region was the focus for our local media research : as well as being the home base of the research team, it is an area where women's football, the most popular team sport, is strong. The Head of Sport, BBC English regions, Charles Runcie, said 'I try to encourage as much diversity in local coverage at all times' (email communication, 3 December 2007). Perhaps tomorrow's heroines of the sporting arenas will be nurtured and championed at the local level, in hometown evening papers and local radio stations, or perhaps this is where they will fail to get off the mark.

\section{Previous Studies}

Most previous studies into coverage of female sport have tended to focus on the national or transnational level, either looking at particular sports or large events like the Olympics (Higgs and Weiller 1994; Billings and Eastman 2002; Capranica et al 2005). The general conclusion of the majority of these papers is that there is a large imbalance in the coverage of male and female sports, both in terms of the amount of space they receive in the media, and the way they are portrayed (Bryant 1980; Jones et al 1999). In the rare instances where male and female coverage of a sport is slightly more balanced, for instance tennis, the female athletes are often portrayed in a sexist and condescending manner (Crossman et al 2007; Vincent et al 2007). Generally female athletes are more newsworthy as celebrities, with events like their marriage, or whom they're dating, being granted higher status then their sporting achievements. Some authors have even argued that coverage of female sports is specifically geared towards only covering female sporting events that are deemed 'feminine' (Kane 1989) and that this can help reinforce the negative perception that women are not as good at sport as their male counterparts (Bryson 1990) and therefore not worth watching. This trend appears to be present in almost all Western nations to a greater or lesser extent and the UK is certainly not immune (George et al 2001).

The most popular sport in England is by far football and there has been a growing number of female teams and players for the past few years. However the coverage seems to remain lopsided (Harris 1999) which has had a corresponding knock-on effect for female participation and attitudes towards the game (Harris 2005).

Various reasons have been put forward to explain why there is this continuing imbalance. These include the simple fact that commercial factors shape media coverage. Participation in team sports is far lower among women than men. Another reason suggested is the lack of female journalists employed by newspapers and magazines (Hardin and Shain 2005).

\section{Context}

\section{Football in the UK "quite unsuitable" for women}

The absence of women from history books is nowhere more obvious than in English football. At one time, women's football matches here drew bigger crowds than men's. In 1920 53,000 spectators attended a women's football match at Everton's Goodison Park, and a further 14,000 were turned away (FA 2011). However, or perhaps as a 
consequence of this, the Football Association banned females from playing on their grounds in 1921. Committee members decided that '...the game of football is quite unsuitable for females and ought not to be encouraged' (FA 2011).

There is evidence that while female participation in football is on the rise again, it is currently hampered by on-going gender issues within society and the media's lack of positive coverage. According to FIFA, there are 26 million females playing across the world, of which 4.1 million are playing affiliated football - this is a 54 per cent growth since the year 2000 (FIFA 2006). The Football Association (FA 2013a) states female football is the country's fastest growing sport, with 8,500 women's and girls' teams in England in 2008, an increase of more than a hundredfold in just 15 years (Sport England 2009) (Table 1). Locally, one in ten children and one in nineteen adults playing football in FA-affiliated teams in Nottinghamshire are female (5.5 per cent).

Looking at the popularity issue today, attendance to women's events is generally often poor with Nottingham Forest Ladies FC at home to Arsenal Ladies in 2009 drawing less than a hundred spectators. The few exceptions to this rule occur when the matches are televised or mentioned on the news. The same fixture the following season attracted a crowd of more than 600 , following a feature on BBC regional television. The FA cup final, staged in Nottingham in 2009 , previewed widely on national media, was attended by nearly 25,000 , packing out the City Ground, watched by 1.4 million on BBC national television. The women's football gold medal final at the 2012 Olympics in London between the USA and Japan was watched by a live audience of more than 80,000 , according to the BBC the biggest crowd in the UK ever recorded for a women's football match. Meanwhile a survey by the Women's Sport Foundation showed that $61 \%$ of sports fans would watch more women's sport if it were televised (WSFF 2010, 5).

\section{Equality}

Western liberal tradition tells us we're equal and independent, but gender studies suggest that the playing field is by no means level (Bock and James 1992, 52). Furthermore they indicate that if 'males' have a monopoly of power overall, (Phillips 1991, 79), they will also have it in areas such as politics, the media and sport. Types of gender are forged and constantly recreated through contact with others (Connell 2002, 164) and sports such as yoga and jogging are blurring boundaries of gender identity (Whitson 2002, 238). But in spite of shifts in gender roles, inequality thrives (Zoonen 1994, 150) and the coverage of football and other sport seems on the surface to stay much the same. Could it be that changing sports reporting habits is considered a serious threat to male hegemony?

\section{Business}

To understand the gendered framework behind sport and the media, it's necessary to mention structures, and above all, economic ones. The global economic system, can be described as 'male' in terms of its interests and character, in that a 'transnational business masculinity' is dominant (Connell 2000, 54) As sport gets increasingly commodified (Whitson 2002, 236) the more identified with masculinity it becomes. Male teams become brands with set slots in the schedule. Strategic rationalisation has taken over from a community approach to the organisation of sport in modern society (Theberge 2000, 279) which clearly disadvantages female sport. According to Jones, 
'women's visibility threatens to disrupt the system of international (dis)order based on competition' $(1990,812)$. We should not be surprised then, if institutions of sport and media, such as the FA, FIFA, BBC, Sky TV and other corporations, in which men are central and women peripheral, sustain male hegemony, as Connell notices elsewhere (2000, 98). So we encounter one of the key battlegrounds of gender : the sports institution, where women's roles are 'an object of constant ideological struggle.' (Pirinen 1997)

\title{
Media
}

The International Women's Media Foundation says its mission is to strengthen the role of women in the news media around the world, based on the belief that no press is truly free unless women share an equal voice (IWMF 2013). The media has long been part of feminism's cultural and material struggle (Zoonen 1994, 148) yet still characterised as 'patriarchal' in the twenty-first century (Scraton and Flintoff 2002). The reluctance encountered during this research by sports editors to include women's activities at all in sports news only confirms this.

In the past, women's issues have been presented as private, domestic matters in the media, so that sport, like news, is not supposed to interest them (Carter, Branston, Allan 1998). Surveys of sources and staffing indicated that "news is not simply mostly about and by men, it is overwhelmingly seen through men' (Hartley 1992). The ratio of men to women in the sports industry and in the media may also determine the scale and type of coverage. It has been claimed until recently that the day-to-day culture of most newsrooms is still being defined in 'male' terms (Carter et al 1998), partly as a result of the predominance of men in positions of power, such as editorial, management and ownership. Coverage arguably won't change until women enter the sphere in numbers. But the sheer presence of females may not change sports news.

\begin{abstract}
'More women in the industry is not enough. There need to be women with a more politicised understanding of the ways in which women's subordination is currently reproduced, and with the will to change it'. (Arthurs 1994)
\end{abstract}

Sports reporting, like all journalism, faces a dilemma between public service and commercial pressure, in a climate of increasing market forces. The effect of a globalized economy is more commercialisation in journalism, increasing the feminization and sexualisation of women as it narrows the range of content. Reducing jobs and resources arguably affects women worst as they are more likely to work parttime. (Carter, Branston, Allan 1998; Chambers, Steiner, Fleming 2004). On the sports desk, our interviews showed that women's sport, already regarded as one of the minority sports, is likely to get less, not more attention. Whether it is best to leave it up to those editors to provide coverage (Van Every 1996), look for and create other media outlets (Theberge 2002,300) or challenge the present structures are more pertinent questions than ever.

\section{Sport}

Media create the social world, (Zoonen 1994) of which sport is a part, so are at least partly responsible for presenting sport is overwhelmingly 'male'. But in any case, the citizen is 'male' (Jones 1990, 784) and sport particularly so, because it enables the 
articulation of masculinity through aggression (Connell 2000), which in itself is held up as a masculine ideal (Jones 1990). Indeed men's football in England is portrayed as a 'martial masculinity,' identified with war and nationality, symbolising superiority and reasserting gender privilege (Pfister 2002). Studies have shown that sport can be such an important cultural space to male identity that it is actually equated to masculinity (Sabo and Runfola 1980). This does not confine itself to symbols though, as even 'Physical power confers social power' (Whitson 2002, 237). There are also signs that sport provides not only a social haven, but an emotional one, as some types of almost hysterical radio commentary of men's matches suggest.

As Talbot notes, $(2002,283)$ 'Sport lags behind all other areas of social or cultural life in respect of gender equity.' Indeed, women's football 'seemed to upset the gender order' when it came on the scene (Pfister 2002). Women's sport in general can be seen as an unwelcome and confusing disruption or subversion of known masculinities (Connell 2000, 96). It may even be feared and rejected as a perversion or a parody, which may help explain its exclusion from the media. There's also evidence that 'men' will try to keep 'women' away from their preserve (Walker 1998).

\section{Local}

The sports pages are the most widely read section of the local press (Sabo and Runfola 1980). It was this paper's hypothesis that local media would report more women's sport on average than the national media, because of its heightened sense of community. Local newspapers cover all manner of local people's achievements from baby shows to wedding announcements. Local media often promote and support local talent and home-grown heroes, such as BBC Radio Nottingham's campaign to back former Nottingham Forest manager, Paul Hart. Our research would find out how far local media conformed to the national pattern of gendered institutions and culture.

\section{Scope and limitation of research}

This paper seeks to examine the amount of coverage of women's sport at local level in the East Midlands of the UK. Time and resources have not allowed for an attempt to assess the quality of the reporting. The East Midlands was chosen because it has a reasonably strong tradition of women's sporting participation and interest. The women's FA cup has been held three times in the region in recent years, so if the fastest growing sport, women's football, is going to be well represented, it could be here.

Most research up to now has looked at either newspaper or TV, with very few examining radio broadcasting, despite it being a hugely popular medium for sports coverage in the UK. Previous studies have concentrated on a single, contained event like the Olympics because it's more manageable, but such occasions don't always give a nuanced view of on-going sporting coverage. It's the equivalent of trying to draw conclusions about how politics operates in a country by only studying elections.

There are some limitations to this type of study. Relevant data quickly becomes out of date and there are as yet no comparable surveys on local media. While wordsearches for articles are useful, they are not an exact science. The scope for online data analysis of local newspapers is confined to a narrow archive. However, this study is able to provide some very clear data for the first time on the current situation for a 
representative region and highlight some trends at an interesting and unpredictable moment for women's sport in England. We do not attempt with this research to explain at length why coverage is how it is, but to suggest some reasons.

\section{Methodology}

Quantitative and qualitative methods were used, including word searches online and interviews. Meanwhile, the coverage itself of women's sport was assessed by looking at BBC local radio and the main local newspapers. Coverage over time periods in the same media outlet was examined to spot trends. The study also attempted to gauge interest in media coverage of female events by interviewing relevant people in the industry and media, including participants, sports leaders and journalists and by monitoring various outlets.

Four local BBC radio stations were studied, namely Radio Nottingham, Radio Leicester, Radio Lincoln and Radio Derby. These are the main news and sports broadcasters in each county, but also part of a media organisation with strong commitment to public service. Commercial radio was not included. Researchers searched for 'sport', 'football', 'women' and 'ladies' in the sports news. They counted the number of items about women's and men's sport and football in sports bulletins over various time periods. The number of hours of weekly sports programming devoted to women's and men's sport was also compared.

A brief survey of all BBC local radio stations' women's local football coverage was undertaken by telephone and email, to explore national patterns. This showed that the local area of study was fairly representative of the general picture of BBC local radio coverage, judging by its reporting of women's football results and fixtures. In terms of representation on the sports desk, the study tried to ascertain the number of women in sports editor roles in local radio through interviews.

The Nottingham (Evening) Post, Leicester Mercury, Lincolnshire Echo and Derby (Evening) Telegraph were examined as the four main online daily papers for the East Midlands region. The number of articles over a four year period on female sport and female football was noted, and whether there was any increase or decrease in that number over time, comparing each month separately.

To complement this work, audio and email interviews were carried out with relevant people in media and sport to explore the nature of coverage, reasons for it and possible solutions. They included sports editors, journalists, female players, coaches and students.

\section{Data results :}

\section{Sport on local radio}

The main local radio speech broadcaster in the East Midlands area is the public service network, the British Broadcasting Corporation (BBC). Firstly, to get an idea of general sports coverage, a snapshot of one week's sports bulletins was looked at across the four relevant stations in the region, from 19-26 November 2009. Records are archived on ENPS (Essential News Production System), the BBC's internal electronic database 
provided by the Associated Press. An examination of its electronic records of sports news and programmes running orders demonstrated a huge imbalance in terms of the number of stories devoted to male and female sports. Figures suggest that on average, 5.63 per cent of sports news is about women's sports, (Table 2) which roughly corresponds to the data from the 2003 survey on national media

\section{Football on local radio}

Some sports editors claimed in interviews to report regularly on their women's football results and fixtures, including commentary of live games. However, research of sports bulletins shows a tiny amount of items on women's sport compared to men's :

\section{In sports bulletins}

The early morning sports bulletins running orders at all four BBC local radio stations were observed, using an ENPS search of key words (Table 3). The study is based on an average week in late September 2009, in order to get a picture of normal coverage once the football season was well underway. Research of these sports (not news) bulletins indicate that $\mathbf{0 . 9 5}$ per cent of local radio football news is about women's football. (It should be noted that the actual number of stories about women's football in one year are shown next to an approximation of the number of stories about men's football, based on the weekly snapshot). It's interesting to record that the name Derby County Ladies (the most successful women's team in the station's patch) could not be found on a word search on ENPS in Radio Derby Sport from 14/5/09 to 23/4/11, so for almost two seasons. There was no other women's sport apart from football which featured significantly either.

In addition, BBC local stations across England were asked in a survey in 2007 (by email and telephone) whether they regularly reported on the fixtures and results of their local women's football teams. The results were very patchy. Approximately a third of stations' sports desks claimed they did, and two thirds didn't. There didn't seem to be any consistent reason for this approach - they did in Liverpool, London, Lincolnshire and the Channel Islands, but not in Nottingham or Bristol, both of which had premiership sides.

\section{In sports programmes}

Looking in more detail at a particular week of programming (ie sports shows, rather than sports news bulletin summaries) during the football season gave us another angle. The survey over the week commencing 11 Sept 2010 showed that no minutes of the sports programming on local radio stations in the region was devoted to women's sport, let alone football, (Table 4), while up to 18 hours a week was spent on men's events. There was generally no coverage on the stations' website either.

In interviews, Charles Collins of BBC Radio Derby Sport said cup games were reported, but that coverage 'all depends on a) success and b) demand'. Radio Nottingham sports presenter Robin Chipperfield explained similar reasoning behind his decision to run a story on Nottingham Forest Ladies : 'It's on an editorial basis, if there's a big game or if they need to win the game to stay up or get promotion'. Ian Stringer of BBC Radio Leicester said 'There isn't as much coverage of the women's 
game as the men's because there's not enough interest'. At Trent FM (the local commercial station with the biggest audience in Nottingham at that time) the news and sport spokesman said they never covered women's football, but not because of lack of staff : 'Resources isn't the issue, even if we had more reporters the station just wouldn't do it. The BBC has more of a remit for covering minority sports'. Sports correspondent for $\mathrm{BBC}$ regional television flagship programme, East Midlands Today, Natalie Jackson, described coverage as 'pretty fair' and cited audience demand and resources as the issue : 'In terms of local coverage I don't think we will broadcast more until crowds improve'.

As a result women's football seems to be trapped in a vicious circle. Journalists may admit that there is a significant imbalance in coverage but most will not change practice until there are bigger crowds. This in turn won't happen without more coverage. What is particularly interesting is the lack of coverage by the $\mathrm{BBC}$, whose diversity policy states : 'We aim to reflect the totality of the nation through our output.'

\section{Football in local newspapers}

The four local newspapers with the largest circulations in the East Midlands were studied, namely the Nottingham Evening Post, The Leicester Mercury, the Derby Evening Telegraph and the Lincolnshire Echo. Looking on a month by month basis from 2008 to 2010 (inclusive) our research showed a very low number of stories about women's football - around 15 per year (Table 5). This is despite there being several sizable football clubs in the region such as Nottingham Forest Ladies.

Looking in more detail, the number of articles on women's football varies from one year to the next, sometimes increasing, but a monthly comparison shows that the increases are not consistent : in fact for three years (between 2008 and 2010), there was no overall monthly increase in any of the four papers in the East Midlands, while in Derbyshire there was a decrease. There were 17 months when the Leicester Mercury had no articles on women's football; 15 months in the Lincolnshire Echo; 10 in the Derbyshire Evening Telegraph and 8 in the Nottingham Evening Post. In the DET, there was a sharp decline in coverage between 2009 and 2010, when 14 articles were published - less than a third of the number in the previous year (Table 6).

However, if figures since 2011 are added to the study, there are indications of a slight rise in the number of articles, albeit in an odd pattern. A number of articles on women's football relate to the introduction of the Women's Super League in April 2011. Most notably, the Lincolnshire Echo, home to Lincoln City Ladies, the only team in the region in the WSL, includes several reports on this. (Table 7). Curiously, the number of articles dips soon after the season starts (Table 8).

\section{Representation on sports desks}

There seems to be a clear bias towards male staffing on the sports desk. Nationally there is wide under-representation : our enquiries in 2008 indicated that only one daily newspaper had a woman sports editor. Only one sports editor in BBC local radio, which has more than 50 stations, was female. The London Evening Standard had five full-time staff, none of them female, according to its sports editor in a survey email response. When asked whether his paper regularly reported the fixtures and results of 
women's football matches in London, home of several premiership sides, Steve Cording's answer was "No."

\section{Interviews 2}

Interviews with participants and those with a sports interest indicate that not everyone has growing enthusiasm for coverage of women's football in the current media set up. Amy White, Nottingham Forest Ladies senior team player suggests a separatist approach : 'I think women and girl's football is growing incredibly quickly and will continue to do so. I would say it's better to watch then men's as its not prominently based on strength, speed etc'. TalkSport radio journalist, David Currie noted that the 2010 FA cup final provoked a lot of interest but appears to deny responsibility for adjusting coverage himself. He said, 'That just shows that there is a place for women's football and certainly an interest and a need for increased coverage, but it's a case of how quickly that coverage will come about'. However, football coach Ross Freeman thinks the current coverage is spot on, as it is in line with market forces, 'I don't think it needs to change because there's not much of an audience for it. Surely it's a minority that are going to want to read about it'. He's not the only industry professional who takes this view. Metro Radio news journalist, Simon Conway argues that the lack of coverage is the fault of the sport itself, 'Like many women's sports, it's just not as an exciting a game as men's football'. As Pirinen points out (1997) comparing men's and women's ability at a sport in which they would never compete against each other might seem irrelevant. Simon Conway's view would be disputed by some but reflects the opinion of many sports journalists interviewed, who did not see the point of including women's experience.

At the moment, the suggestion from the industry seems to be that women should change their behaviour in order to get into the media. They either need to make their sport 'more exciting' or bring a bigger audience with them. Like media organisations studied previously, these local outlets 'fail to own the issue of inequality' and are antichange, (Talbot 2002, 282). Equality may be thwarted by the 'masculine fundamentalism' observed by Connell (2000) which appears to have entrenched itself in response to the growth of women's sport. There are few challenges to male hegemony on the local level here and even exceptions to the rule, (such as BBC Radio Merseyside, which unusually broadcasts live commentary of women's games), appear to have no impact on their sister stations' output.

\section{Conclusion}

The results of the research show patchy, irregular coverage of women's sport in local media. The frequency of local coverage of women's football, reportedly the country's fastest growing sport, is negligible compared to that of men's. The monthly rate of local newspaper articles about it seems to be either staying the same or declining, in spite of a surge of female interest and participation. There seems to be no policy or consistency in reporting women's sport, in contrast to the routine formats of men's sports coverage. In many cases the percentage of local coverage was far lower than in the national media. However there are also indications of spasmodic increased interest in women's football in the last two years, some of it apparently related to the launch of the new Women's Super League. However, pockets of progressiveness, such as in Liverpool or Lincolnshire, have not helped bring about equality elsewhere. 
The exclusion of women from sports coverage is even greater than it appears in these tables, because what isn't taken into account is the vastly increased coverage of men's sport, on DAB radio, TV and online. Even though women's participation has increased, 'areas of exclusion are multiplied' (Cranny-Francis et al 2003).

\title{
Towards an explanation
}

The reasons for lack of coverage do not all appear to be commercial, with football crowd numbers not always translating into column inches or airtime. For example, up to three thousand people have attended Arsenal Ladies matches, while a non-league male side might not attract five hundred spectators, but is guaranteed live match commentary and hours of regular programming on local radio.

Natalie Grundy, an ex-footballer, blames both ignorance and prejudice :

\begin{abstract}
'I don't think women's football gets enough coverage, I think it's just as important as the men's and sometimes the games are be better. It's just sexism really. It all stems back to the equal pay debate, for example the England Captain Kelly Smith doesn't get paid anywhere near the amount that Steven Gerrard does. The media may assume that people don't want to know about it but there is an audience for women's football definitely.'
\end{abstract}

There's a reluctance to admit females to the fold. One young footballer, Jaye Harrison, commented in interview, 'A lot of young girls are used to the boys saying 'Oh girls can't play football'. The amount of times that I can have a conversation with guys in the pub and they're surprised to find that I can actually speak fluently about football!'

As well as possible gender bias, there is a tendency by journalists to follow the norm or habit. This includes concentrating on clubs with big fan-bases and reporting directly to them. In an increasingly harsh capitalist environment it is the well-branded clubs which hog the limelight. 'Women's football often gets left behind in terms of that coverage because the Premier League dominates,' according to TalkSport's David Currie.

Representation of women in sports journalism, the Football Association and FIFA, the absence of policy or strategy in the sport and media industry and the failure to enforce existing policies or mission statements are also crucial. The WSFF reports that less than $25 \%$ of positions on the boards of most sports insitutions are filled by women (2013) as sport becomes a vast global business.

The lack of local coverage, such as is studied here, not only reveals the marginalisation of women but also has the potential to decrease 'female' power, while increasing 'male'. Previous research has shown that these examples of the 'denial of game' also represent a 'symbolic denial of power' which can be regarded as 'harmful' because they not only exclude women from many benefits but modify culture and social practices (Duncan and Hasbrook 1988).

Most people working in the sports industry know there's inequality even if they pretend not to: there's a keen awareness of 'politically correct' arguments. Perhaps a 
new ability to accept double standards has emerged from 'pc' fatigue. The entrenchment of male dominance in sports coverage could be a temporary response to feminist pressures, as old-style editors escape from new guilt into their favourite haven - sport.

\section{The future}

The figures and interviews here serve as a basis for more study into reporting trends and also on-going investigation into the reasons for the changes in coverage. There is scope for further exploration of media organisations with regard to sports editorial decisions, the gendering of management policy making and staffing. The importance of non-mainstream sports news outlets on the internet could also be explored, such as the women's football website 'femalesoccer.net' which boasts 3.2 million hits a month. It would be interesting to look at the presence of female students and staff on sports journalism training courses. A study of coverage of student sport in varsity publications, which are less subject to financial pressures, might indicate interesting trends.

There is a possibility that coverage will improve with the rise of the internet and satellite TV. ESPN channel has broadcast matches of the expanding English Women's Super League. The higher number of local stories in Lincolnshire since the WSL also signifies a new interest on the sports desks. London 2012 showed that if a women's event is reported prominently, the crowds will come, because the interest is there. It also showed that crowds and schedules can easily change overnight. In a message on International Women's Day 2011, the FIFA president said, 'We have always believed that the future of football is feminine.' Yet premiership side Nottingham Forest Ladies had to rattle buckets at a men's Saturday match as recently as 2009 to help raise $£ 5,000$ to stop them going into administration. Clearly there is much ground to be covered before gender parity's achieved.

It is important for a healthy society to have fair coverage of men's and women's activities in the media. Gender relations need to be more democratic 'to build a more civilised world' (Connell 2000, 6). As Kathleen Jones says, simply counting women is not enough : sports media, like citizenship, should be redefined to include women (Jones 1990). If we are all to be free and equal, 'it is necessary to treat some differently from others,' (James, in Bock and James 1992, 52). Only then can the 'patriarchal dividend' referred to by Connell $(2000,25)$ be redistributed. If the balance is to be redressed (Bock and James 1992), representation of women in sport and media should be increased, and not just to cover more men's sport. It should be noted that any commercial promotion of women's sport to try to please a male audience could make matters worse (Theberge 2002, 300).

Intervention is long overdue to bring about equality of reporting, as most sports editors probably know. It was achieved in Ottawa when The Committee for Gender Equity made changes to varsity Sports Services (Mackay and Dallaire 2009) or when the IOC helped bring about parity in media coverage during the Sydney Olympics (Capranica et al 2005). However it only seems to occur when parallel men's and women's events are staged at the same location. A first step is for institutions to recognise their part in perpetuating the inequalities (Talbot 2002, 282). 
The reason cited most often in the interviews carried out for failure to change reporting habits was the lack of live crowds for women's events. Commercial viability is paramount, even in a non-commercial outlet like the BBC. In the globalised free market, it appears there's no room for anything other than crowdpleasers. As Connell notes, the neo-liberal agenda rejects gender reform (2000, 53). So it seems that above all, macho-economics is preventing change. This raises questions about the role of government to promote diversity in sport and the media or legislate for equality. But the key factor is making structural and material inroads into global institutions and economic systems.

If today's girls continue to play football into adulthood, one in ten people playing the sport in England could be women. It will be interesting to see when or whether their sport, or any other, breaks through into general consciousness via the media, and if so, in what way. Until then, an alien from outer space visiting the East Midlands a few months after the Olympics could easily assume from the local sports media that the female of the human species did not exist.

\section{Acknowledgments:}

This research was possible thanks to a NTU Scholarship Project for Undergraduate Researchers.

\section{Notes}

1. The phrase 'Sport is King' was used by Pierre de Coubertin in his address on the Olympics delivered at Antwerp City Hall in August, 1920, published by IOC in Olympism, 2000, 222. Lausanne. It has also been used as way to describe sport in terms of its financial importance in the global media industry today. According toFIFPRO diversity spokesman, Tony Higgins (personal communication 1 February 2008) countries in the developing world would rather join FIFA than the UN because it confers more status and money.

2. Interviews were carried out in the summer of 2010 by student researchers at Nottingham Trent University

\section{References}

Arthurs, Jane, 1994. Women and television. In Stuart Hood, Behind the Screens London: Lawrence and Wishart.

BBC $\quad$ Sport, $2007 . \quad$ [online] Available from : http://news.bbc.co.uk/sport1/hi/football/get_involved/4246110.stm [ accessed 9 March 2013]

Billings, A.C., Eastman, S. T., 2002. Selective Representation of Gender, Ethnicity, and Nationality in American Television Coverage of the 2000 Summer Olympics, International Review for the Sociology of Sport, 37 (3-4), 351-370

Bock, G and James, S., 1992. Beyond equality and difference : Citizenship, feminist politics and female subjectivity. London : Routledge.

Brown, Sarah. 2012. London 2012 : The women's Olympics? CNN [online] Available from http://edition.cnn.com/2012/08/10/sport/london-olympics-women [Accessed 8 March 2013] 
Bryant, J., 1980. A two-year investigation of the female in sport as reported in the paper media, Arena Review 4, 32-44

Bryson, L., 1990. Challenges to the male hegemony in sport. In M Messner and D Sabo eds. Sport, Men and the Gender Order: Critical Feminist Perspectives, Human Kinetics, Champaign, IL, 173-84.

Burroughs, A, Ashbourne, L., 1995. Add sex and stir: homophobic coverage of women's cricket in Australia. Journal of Sport and Social Issues 19 (3), 266-84

Capranica, L et al., 2005. Newspaper Coverage of Women's Sports During the 2000 Sydney Olympic Games : Belgium, Denmark, France, and Italy. Research Quarterly for Exercise and Sport $76: 212-223$

Carter, Cynthia, Branston, Gill, Allan, Stuart, 1998. News, Gender and Power._London : Routledge

Chambers, Deborah, Steiner, Linda, Fleming, Carole, 2004. Women and Journalism. London : Routledge

Connell, R.W., 2000. The men and the boys. Cambridge : Blackwell

Connell, R.W., 2002. Debates about men, new research on masculinities. In S. Scraton and A. Flintoff eds. Gender and Sport. London : Routledge

Cranny-Francis, A., Waring, W., Stavropoulos, P., Kirkby, J., 2003. Gender Studies. Basingstoke : Palgrave Macmillan

Crossman, J., Vincent, J., Speed, H., 2007. The Times They Are A-Changin - Gender Comparisons in Three National Newspapers of the 2004 Wimbledon Championships. International Review for the Sociology of Sport 42 (1), 27-41

Duncan, M. and Hasbrook, C., 1988. Denial of power in televised women's sports. In Sociology of sport Journal 5 : 1-21

FIFA, 2006. The Big Count 2006. [online] Available from :

www.fifa.com/mm/document/fifafacts/bcoffsurv/bigcount.statspackage_7024.pdf [accessed 9 March 2013]

The Football Association, 2011. Women's Football: A brief history [online] Available from:

www.thefa.com/GetIntoFootball/Players/PlayersPages/WomensAndGirls/History_of womens_football [accessed 9 March 2013]

The Football Association, 2013a. What the FA does. [online] Available from: www.thefa.com/TheFA/WhoWeAre/WhatTheFADoes [accessed 9 March 2013]

The Football Association, 2013b. Women's Football : A brief history [online] Available from : 
www.thefa.com/GetIntoFootball/Players/PlayersPages/WomensAndGirls/History_of_ womens_football.aspx [accessed 9 March 2013]

Hardin, M., Shain, S., 2005. Female Sports Journalists: Are we there yet? "No". Newspaper Research Journal 26 (4), 22-35

Harris, J., 1999. Lie back and think of England. The women of Euro 96. Journal of Sport and Social Issues 23 (1), 96-110

Harris, J., 2005. The Image Problem in Women's Football. Journal of Sport and Social Issues 29 (2),184-197

Hartley, John, 1992. Understanding News. London : Methuen.

Higgs, C.T., Weiller, K.H., 1994. Gender Bias and the 1992 Summer Olympic Games: An Analysis of Television Coverage. Journal of Sport and Social Issues 18 (3), 234-246

Huffman, S., Tuggle, C.A., Rosengard, D.A., 2004. How Campus Media Cover Sports: The Gender-Equity Issue, One Generation Later. Mass Communication and Society 7 (4), 475-489

IWMF mission statement [online] Available from : http://iwmf.org/about-theiwmf.aspx [accessed 9 March 2013]

Jones, K., 1990. Citizenship in a Woman-Friendly Polity. Signs : 15, 781-812

Jones, R., Murrell, A.J., Jackson, J., 1999. Pretty Versus Powerful in the Sports Pages - Print Media Coverage of U.S. Women's Olympic Gold Medal Winning Teams. Journal of Sports and Sporting Issues 23 (2), 183-192

Kane, M.J., 1989. The Post Title IX Female Athlete in the Media. Things are Changing, but How Much? Journal of Physical Education, Recreation and Dance 60 (3), 58-62

MacKay, S. and Dallaire, C., 2009. Campus Newspaper Coverage of Varsity Sports : getting closer to equitable and sports-related representations of female athletes? International Review of the Sociology of Sport 44, 25

Pfister, G. et al., 2002, 66-78. Women and football - a contradiction? The beginnings of women's football in four European countries. In S. Scraton and A. Flintoff eds. Gender and Sport. London : Routledge.

Phillips A., 1991. Engendering Democracy. Cambridge : Polity Press in association with Blackwell.

Pirinen, R., 1997. The construction of women's positions in sport : a textual analysis of articles on female athletes in Finnish women's magazines. Sociology of Sport Journal $13: 290-301$ 
Pirinen, R., 2002, 94-106. Catching up with men? Finnish newspaper coverage of women's entry into traditionally male sports. In S Scraton and A Flintoff eds. Gender and Sport. London : Routledge.

Sabo, D. and Runfola R., 1980. Jock: Sports and male identity. Englewood Cliffs, NJ : Prentice-Hall

Scraton, S. and Flintoff, A., 2002, 30-47. Sport feminism: The contribution of feminist thought to our understandings of gender and sport. In S Scraton and A Flintoff eds. Gender and Sport. London : Routledge.

Sport England Active People Survey 4 2009/10 [online] Available from : www.sportengland.org/research/active_people_survey/active_people_survey_4.aspx [accessed 8 March 2013]

Talbot, M., 2002, 277-291. Playing with patriarchy : the gendered dynamics of sports organizations. In S Scraton and A Flintoff eds. Gender and Sport. London : Routledge.

Theberge, N., 2002, 292-302. Challenging the gendered space of sport : women's ice hockey and the struggle for legitimacy. In S Scraton and A Flintoff eds. Gender and Sport. London : Routledge.

Topping A., 2012. Women's sport is underfunded and ignored, charity claims. The Guardian, 24 October. [online] Available from : www.guardian.co.uk/lifeandstyle/2012/oct/24/womens-sport-underfunded-ignoredcharity-claims [accessed 11 March 2013]

Vincent, J., Pederson, P., Whisenant, W., Massey, D., 2007. Analysing the print media coverage of professional tennis players: British newspaper narratives about female competitors in the Wimbledon Championships. International Journal of Sport Management and Marketing 2 (3), 281-300

Walker, L., 1998. Under the bonnet : Car culture, technological dominance and young men of the working class, Journal of Interdisciplinary Gender Studies 3 : 23-43.

Wann, D.L., Schrader, M.P., Allison, J.A., McGeorge, K.K., 1998. The Inequitable Newspaper Coverage of Men's and Women's Athletics at Small, Medium, and Large Universities. Journal of Sport and Social Issues 22 (1), 79-87

Whitson, D., 2002, 227-240. The embodiment of gender : discipline, domination, and empowerment. In S Scraton and A Flintoff eds. Gender and Sport. London : Routledge.

WSF, 2003. Women's Sport Foundation. WSF slams "appalling" media coverage of female sport in Britain [online] Available from :

http://www.docstoc.com/docs/27902136/womens-sports-foundation-news-release-

embargo-0001-wednesday-19

[accessed 9 March 2013]

WSFF, 2009. Womens Sport and Fitness Foundation, WSFF Celebrates 25 Years in Women's Sport, [online] Available from : 
www.wsff.org.uk/news-and-views/wsff-celebrates-25-years-in-womens-sport [accessed 9 March 2013]

WSFF 2010. Womens Sport and Fitness Foundation. Annual review 2010. [online\} Available from : www.wsff.org.uk/resources/wsff-reports-and-events/annual-review$\underline{2010}$ [accessed 9 March 2013]

WSFF 2013. Womens Sport and Fitness Foundation, Trophy women? NGB Leadership Audit 2013. [online] Available from :

www.wsff.org.uk/news-and-views/media [accessed 9 March 2013]

Zoonen, L. Van., 1994. Feminist Media Studies. London : Sage. 